\title{
Ensino de filosofia e ensino de ciências: um estranho silêncio
}

\author{
Philosophy and science teaching: a strange silence
}

\author{
Caio Seiji Nagayoshi \\ Doutorando na Universidade de São Paulo, São Paulo, São Paulo, Brasil. \\ caio.nagayoshi@gmail.com

\section{Daniela Lopes Scarpa} \\ Professora na Universidade de São Paulo, São Paulo, São Paulo, Brasil. \\ dlscarpa@usp.br - https://orcid.org/0000-0002-7720-7611
}

Recebido em 08 de janeiro de 2018

Aprovado em 16 de abril de 2018

Publicado em 17 de agosto de 2018

\begin{abstract}
RESUMO: Na área de ensino de filosofia, poucos trabalhos têm sido publicados com foco no ensino de filosofia da ciência. Contudo, na área de ensino de ciências, há amplo reconhecimento de que a introdução de elementos de filosofia da ciência na escola pode contribuir para a alfabetização científica. $O$ argumento é de que não basta que os alunos aprendam conceitos científicos; eles devem aprender, também, sobre a atividade científica e o conhecimento científico por ela produzido, isto é, sobre a natureza da ciência ( $\mathrm{NdC})$. O presente artigo apresenta um breve panorama das pesquisas sobre o tema na área de ensino de ciências. Argumenta-se que, apesar da atual falta de comunicação entre as áreas de ensino de filosofia e ensino de ciências, um maior diálogo entre elas seria benéfico para ambas. Palavras-chave: Ensino de Ciências, Ensino de Filosofia, Filosofia da Ciência, Natureza da Ciência.
\end{abstract}

ABSTRACT: In the field of philosohy teaching, few texts have been published focusing the teaching of philosophy of science. However, in the field of science teaching, there is wide recognition that the introduction of elements of philosophy of science in school can contribute to scientific literacy. The argument is that it is not enough for students to learn scientific concepts; they must also learn about scientific activity and the scientific knowledge produced by it, that is, about the nature of science (NOS). The present article presents a brief overview of the research on the topic in the field of science teaching. It is argued that, despite the current lack of communication between the fields of philosophy and science teaching, a greater dialogue between them would be beneficial for both. Keywords: Philosophy teaching, Science Nature, Science Philosophy, Science Teaching.

\section{Introdução}

O Brasil viu, nas últimas décadas, um crescente movimento de articulação e consolidação da comunidade de educadores e pesquisadores em ensino de filosofia, sobretudo a partir do estabelecimento da obrigatoriedade legal da disciplina no Ensino 
Médio, em 2008. Tal movimento se manifesta, por exemplo, no surgimento de periódicos dedicados publicar especificamente trabalhos na área de ensino de filosofia (como a Revista do NESEF Filosofia e Ensino, de 2013, ou a Revista Digital de Ensino de Filosofia, de 2015), além dos inúmeros livros, capítulos e artigos publicados em revistas de educação, filosofia ou interdisciplinares. Tais trabalhos, por sua vez, enfatizam diferentes aspectos do ensino de filosofia. Há, contudo, dimensões do ensino de filosofia sub-representadas na literatura da área. Entre elas, podemos destacar a filosofia da ciência.

Embora seja possível encontrar textos enfocando o ensino de filosofia da ciência na literatura especializada (vide, por exemplo, PLASTINO, 1986), bem como alguns que procuram estabelecer relações entre filosofia da ciência e ensino de filosofia (por exemplo, OLIVEIRA, 2017), tais trabalhos são raros e esparsos. Se, contudo, voltarmos nossa atenção às pesquisas em ensino de ciências, um contraste marcante pode ser observado. Há décadas, os pesquisadores em ensino de ciências vêm não só buscando referências na história e na filosofia da ciência, mas também pensando em formas de introduzir elementos dessas disciplinas nas aulas de ciências. A expressão "natureza da ciência" (NdC) surge aqui como referência ao principal campo de pesquisa que parte da premissa de que a história e a filosofia da ciência podem contribuir significativamente para a educação científica. Trata-se de uma área de pesquisa efervescente, com produção expressiva na literatura nacional e internacional. Apesar de se tratar de um movimento marcante que reconhece a contribuição da filosofia da ciência para a educação, a área de ensino de filosofia no Brasil tem se mantido silenciosa com relação a essas discussões. O que parece haver é uma falta de comunicação entre duas áreas de pesquisa com temáticas convergentes.

O presente artigo apresenta um breve panorama das pesquisas envolvendo história e filosofia da ciência no ensino de ciências, com especial foco nas discussões sobre natureza da ciência. Embora existam trabalhos sobre filosofia da ciência e NdC no Ensino Superior, o foco aqui será dado à Educação Básica.

Defende-se que a área de ensino de filosofia não deve manter-se alheia a tais discussões e argumenta-se a favor de uma maior interação entre essa e a área de ensino de ciências, com benefícios para ambas.

\section{Natureza da ciência e alfabetização científica}

Há, hoje, na literatura em ensino de ciências, amplo consenso de que não basta ao aluno aprender conceitos científicos; ele deve também compreender minimamente o que é a própria ciência como atividade humana, as características do conhecimento científico e o processo de sua produção. Ou seja, o aluno não deve apenas aprender ciência, mas também aprender sobre a ciência. A expressão "natureza da ciência" refere-se a essa dimensão metacientífica que, entende-se, deve fazer parte do ensino de ciências. Segundo Hodson (2014), a história da presença da ideia de natureza da ciência no currículo está intrinsicamente ligada à noção de "alfabetização científica". Segundo o autor, é possível encontrar referências a propostas curriculares que englobam aspectos de $\mathrm{NdC}$ (ainda que o termo não seja 
empregado) já em fins do século XIX e início do século XX. Embora a alfabetização científica seja frequentemente tomada como o grande objetivo do ensino de ciências, sua definição exata ainda é tema de debates na literatura.

Sasseron e Carvalho (2011) argumentam que há discordância, inclusive, sobre qual seria o melhor termo para designar o conceito ("letramento científico" e "enculturação científica" seriam outros candidatos). Contudo, independentemente do termo que seja utilizado, as autoras identificam três eixos estruturantes comuns às diferentes nomenclaturas: a "compreensão básica de termos, conhecimentos e conceitos científicos fundamentais"; a "compreensão da natureza das ciências e dos fatores éticos e políticos que circundam sua prática"; e "o entendimento das relações existentes entre ciência, tecnologia, sociedade e meio-ambiente" (SASSERON; CARVALHO, 2011, grifo nosso).

De maneira geral, o argumento amplamente aceito em favor da inclusão de aspectos da NdC no ensino de ciências admite que o seu conhecimento é essencial para a alfabetização científica, que, por sua vez, se faz necessária para que o sujeito possa exercitar plenamente sua cidadania num mundo cada vez mais impregnado de ciência e tecnologia. Ou seja, entende-se que o cidadão deve ter um entendimento mínimo sobre o conhecimento científico e o funcionamento da própria ciência para tomar decisões tanto na sua vida pessoal como na esfera política com relação a questões científicas (HODSON, 2014; JENKINS, 2013). Uma vez aceita a importância de se incluir a NdC no ensino de ciências, o movimento natural da comunidade de educadores em ciências foi e continua sendo o de buscar referências nas disciplinas meta-científicas, tais quais a história e a filosofia da ciência.

\section{História e filosofia da ciência no ensino de ciências}

Ao olharmos para o percurso das discussões sobre NdC no ensino de ciências, é possível observar o aporte de disciplinas como a história e a filosofia da ciência. Após a segunda guerra, a urgência do desenvolvimento científico e tecnológico deu grande impulso às pesquisas em ensino de ciências nos países desenvolvidos, em especial nos EUA. Matthews (2004) argumenta, contudo, que a comunidade de pesquisadores em ensino de ciências se apropriou tardiamente das discussões em filosofia da ciência. Assim, nos anos 1950 e 1960, a visão de ciência por trás da elaboração de currículos era influenciada principalmente pelas ideias positivistas da primeira metade do século. Já as ideias de Thomas Kuhn teriam se tornado a principal referência filosófica para o ensino de ciências a partir do final da década de 70 (DUSCHL; GRANDY, 2013; MATTHEWS, 2004).

O reconhecimento das potenciais contribuições da história e da filosofia da ciência ganharam cada vez mais força a partir da década de 80, e em 1987 é fundado o International History, Philosophy and Science Teaching Group, que até hoje reúne historiadores, filósofos e educadores de ciências. O grupo é responsável por conferências internacionais sobre o tema e pela publicação do periódico Science \& Education, voltado exclusivamente para contribuições da história e filosofia para o ensino de ciências. Em 1994, Michael Matthews publicou o livro Science Teaching: The Role of History and Philosophy of Science (MATTHEWS, 1994), que teve sua segunda edição comemorativa de 20 anos lançada recentemente (MATTHEWS, 2015). Também foi publicado o International Handbook of Research in History, Philosophy and Science Teaching (MATTHEWS, 2014) que reúne textos de pesquisadores de diversos 
países sobre o tema. Hoje, temas como "história e filosofia da ciência" e NdC são linhas de pesquisa previstas em diversos programas de pós-graduação em educação e ensino de ciências no Brasil e no mundo, bem como temáticas previstas nos principais congressos nacionais e internacionais, tais como o Encontro Nacional de Pesquisa em Educação em Ciências (ENPEC), Annual International Conference da National Association of Research in Science Teaching (NARST), a conferência da European Science Education Research Association (ESERA), entre outros.

\section{Natureza da ciência: desenvolvimentos recentes, perspectivas, debates}

Como mencionado, um dos principais impactos da história e da filosofia da ciência no ensino de ciências se dá por meio da presença de NdC na Educação Básica. Uma vez reconhecida a importância de que os alunos tenham uma compreensão mínima da NdC, foi natural que os pesquisadores começassem a investigar as concepções sobre ciência desses alunos. Foram desenvolvidos inúmeros métodos empíricos (como questionários, entrevistas, etc.) para investigar as concepções que estudantes de diferentes níveis educacionais possuem com relação à NdC (LEDERMAN; BARTOS; LEDERMAN, 2014). Segundo Lederman (1992), tais pesquisas empíricas foram consistentes em mostrar que alunos em geral possuem concepções sobre ciência que podem ser consideradas problemáticas ou até mesmo ingênuas do ponto de vista filosófico.

Exemplos de tais concepções incluem a noção de que o conhecimento científico corresponde à verdade absoluta e imutável, a ideia de que teorias científicas são apenas conjecturas que se transformam em leis uma vez que se acumulam evidências o suficiente para prová-las, a crença de que há um método científico universal concebido como uma sequência rígida de passos a ser seguida por todos os cientistas que os levaria a descobrirem verdades científicas, entre outras. Ainda segundo o autor, a percepção de tal situação levou os pesquisadores a focarem esforços na elaboração e avaliação de currículos que contribuíssem para a superação daquelas concepções de $\mathrm{NdC}$; nas concepções de $\mathrm{NdC}$ de professores (que também se revelaram problemáticas); e no desenvolvimento e avaliação de intervenções na formação de professores de ciências com foco em NdC (LEDERMAN, 1992). Até hoje, muitas das pesquisas em $\mathrm{NdC}$ no ensino de ciências ainda enfocam uma ou mais dessas mesmas temáticas (para uma revisão recente, vide AZEVEDO; SCARPA, 2017).

Evidentemente, a necessidade de se ensinar aos alunos sobre a NdC suscita as questões "qual NdC ensinar?" e "como fazê-lo?". Como mencionado anteriormente, os educadores em ciências buscam em disciplinas como a história e a filosofia da ciência referências para ajudá-los a responder a perguntas como essas. Da perspectiva da filosofia da ciência, fica claro que a tentativa de caracterizar a atividade científica e o conhecimento por ela produzido se desdobra em inúmeras questões que dizem respeito a diferentes aspectos da ciência, tais como o método científico, a noção de progresso, o problema da demarcação, a natureza das teorias científicas (sem mencionar outros problemas filosóficos aí implicados, tais como a impregnação teórica da observação, a subdeterminação teórica, o debate realismo versus antirrealismo, etc.). Além disso, cada uma dessas questões admite uma variedade de respostas por parte de diferentes filósofos. Como, diante da complexidade destas questões e da pluralidade de posicionamentos filosóficos possíveis, definir o que deve ser ensinado aos alunos da educação básica? 
Alguns autores consideram que tais discussões filosóficas são complexas e densas demais para o aluno da Educação Básica, além de serem irrelevantes para o público geral. Tais autores defendem que seria possível elaborar uma lista de afirmações sobre ciência tão gerais que seriam consensuais entre os filósofos e historiadores da ciência e, ao mesmo tempo, seriam relevantes e acessíveis para estudantes da Educação Básica.

[...] tais discordâncias, mesmo que sejam o alimento do debate acalorado entre filósofos, historiadores ou educadores de ciências, são irrelevantes para a prática da sala de aula [...]. O que é necessário, ao considerarmos a $\mathrm{NdC}$, assim como é o caso do conteúdo científico típico, é a sua adequação educacional, assim como sua apresentação de uma maneira que esteja conectada com as vidas dos estudantes, mas num nível aceitável de generalidade [...]. Pouca discordância existe entre filósofos, historiadores e educadores de ciências sobre as características de $\mathrm{NdC}$ que se encaixam nestes critérios. (LEDERMAN; BARTOS; LEDERMAN, 2014, p. 973)

Embora diferentes autores tenham proposto diferentes listas (AZEVEDO; SCARPA, 2017), a mais conhecida e influente delas inclui os seguintes tópicos: o conhecimento científico é provisório; a ciência é empírica; a ciência é guiada por teoria; é parcialmente produto da imaginação e criatividade; está inserida num contexto sociocultural; há uma distinção entre observação e inferência; não há um único método científico universal; e há uma diferença entre leis e teorias científicas (LEDERMAN et al., 2002). Desta maneira, muito embora tais afirmações tenham sido inspiradas por temas da filosofia da ciência, esses autores evitam a complexidade e as controvérsias das discussões dos filósofos da ciência ao defenderem que esses são os aspectos da $\mathrm{NdC}$ que podem e devem ser trabalhados ou discutidos na Educação Básica.

Tal proposta, que acabou ficando conhecida como a "visão consensual" ("consensus view") sobre a NdC, recebeu críticas de diferentes autores. Matthews (2012) argumenta que a lista de consensos tende a se tornar mais um conteúdo que os alunos devem memorizar. Ao mesmo tempo, ao contornar as complexidades e controvérsias filosóficas, tal abordagem vai na contramão do desenvolvimento da criticidade dos alunos, poupando-os do exercício de analisar as diferentes questões e posicionamentos e refletir sobre eles. Allchin (2011) aponta que mesmo que os alunos incorporem o conhecimento discursivo da lista de consensos, isso não implica que eles se tornem capazes de analisar situações concretas envolvendo questões científicas em suas vidas cotidianas que demandem que eles tomem decisões informadas. Ainda, Hodson (2014) considera que tais afirmações não são características apenas das ciências. O autor também argumenta que algumas delas são irrelevantes para o trabalho de cientistas (como a distinção entre teorias e leis científicas) e aponta que a distinção entre inferência e observação em muitos casos não é tão clara como a lista de consensos faz parecer.

Algumas alternativas à visão consensual foram propostas na literatura. Allchin (2011, 2013) propõe que a NdC seja ensinada por meio do uso de casos concretos históricos e/ ou contemporâneos através dos quais os alunos teriam contato com uma imagem mais 
genuína do processo de produção do conhecimento científico. Desta forma, os alunos teriam a oportunidade de refletir explicitamente sobre inúmeros aspectos da atividade científica sem ignorar sua complexidade e sem limitar-se a uma lista fechada de aspectos selecionados da NdC. A abordagem proposta por Allchin apresenta ainda a vantagem de ser essencialmente investigativa, na medida em que convida o aluno a acompanhar o desenvolvimento de um episódio histórico (ou contemporâneo) da ciência e a refletir sobre ele sem conhecer de antemão seu desfecho. Contudo, Allchin faz uma ressalva com relação ao tratamento de certos temas filosóficos com os alunos, um ponto ao qual retornaremos adiante.

Outra crítica feita à visão consensual é a de que ela diz respeito à ciência em geral, ignorando as especificidades das diferentes ciências. A partir dessa crítica, Irzik e Nola (2011) propõem aquilo que chamam de "abordagem de semelhança de família", inspirada no conceito homônimo de Wittgenstein. Os autores defendem que as diferentes ciências apresentam semelhanças compartilhadas diferencialmente, isto é, embora não haja uma única característica definidora e compartilhada por todas elas, cada ciência (como a biologia, a química, a física, etc.) compartilha algumas características com umas e outras com outras, de maneira que as diferentes disciplinas científicas guardam uma semelhança de família entre si. Ao abordar o ensino de NdC dessa maneira, fica claro ao aluno que há diferenças importantes entre as várias ciências e, no entanto, há aspectos importantes que nos permitem chamá-las coletivamente de "ciências". Tal abordagem foi posteriormente aprofundada e expandida por Dagher e Erduran (2016) para o uso em sala de aula. A abordagem de semelhança de família se coloca como uma alternativa a algumas das dificuldades encontradas na visão consensual uma vez que leva em consideração a especificidade das diferentes disciplinas científicas e não se restringe a uma lista fechada de aspectos gerais da ciência (DAGHER; ERDURAN, 2016; IRZIK; NOLA, 2011). Contudo, Kampourakis (2016) defende que é possível utilizar a abordagem da visão consensual como ponto de partida para se tratar da $\mathrm{NdC}$ em sala de aula e aprofundar a discussão sobre cada tópico gradualmente, aproximando-se gradualmente da abordagem da semelhança de família. Ou seja, segundo o autor, seria possível articular uma à outra na sala de aula (KAMPOURAKIS, 2016).

Há, ainda, ao menos dois aspectos importantes sobre o ensino de $\mathrm{NdC}$. O primeiro diz respeito à relação entre essa e o processo de investigação científica (scientific inquiry). Enquanto os defensores da visão consensual preferem traçar uma distinção clara entre ambos, empregando o termo NdC exclusivamente para referirem-se a aspectos epistemológicos da ciência, isto é, ao conhecimento científico como produto daquela atividade de investigação (LEDERMAN, 1992), há autores que argumentam que ambos estão intimamente ligados, não podendo ser claramente separados sem prejuízo para a compreensão de um e de outro (HODSON, 2014).

O segundo aspecto diz respeito à adoção de abordagens explícitas ao invés de implícitas defendida por alguns autores (sobretudo no contexto da formação de professores, embora haja estudos que também suportam a mesma medida na Educação Básica) (LEDERMAN, 2007). Abordagens implícitas são aquelas em que os alunos estudam casos históricos ou engajamse em atividades investigativas (como, por exemplo, atividades experimentais em laboratório) sem refletirem e discutirem explicitamente os aspectos de $\mathrm{NdC}$ envolvidos. Abordagens explícitas, por outro lado, envolvem o aluno na reflexão explícita sobre aspectos de $\mathrm{NdC}$. 
[...] os últimos 15 anos foram marcados por uma lenta mas definitiva mudança de perspectiva em relação a como agimos no sentido de mudar as concepções de $\mathrm{NdC}$ de professores. Em resumo, houve uma mudança para abordagens instrucionais mais explícitas na pesquisa relacionada às concepções de $\mathrm{NdC}$ de professores. (LEDERMAN, 2007, p. 854)

Hoje, as grandes questões na base das discussões encontradas na literatura sobre $\mathrm{NdC}$ no ensino de ciências continuam sendo aquelas apontadas anteriormente: o que e como ensinar. Isto é, como deve ser concebida a $\mathrm{NdC}$ a ser ensinada aos alunos e qual seria a melhor forma de ensiná-la? As diferentes abordagens estão na mesa e o debate entre elas continua. Enquanto a visão consensual, outrora bastante influente, parece perder força frente às críticas que foram se acumulando ao longo dos últimos anos, abordagens rivais tendem a enfatizar o contato do aluno com a complexidade da atividade e do conhecimento científicos e a recusar a simplificação excessiva e a redução da $\mathrm{NdC}$ a listas fechadas de afirmações gerais.

Enquanto a importância de se introduzir elementos filosóficos nas aulas de ciências é amplamente reconhecida, é raramente efetivada devido a diversas dificuldades, como insegurança do professor de ciências em tratar do tema (com o qual geralmente se sente pouco familiarizado), ausência da filosofia da ciência na formação docente, carência de material didático específico, entre outros (HÖTTECKE; SILVA, 2011; MARTINS, 2007).

\section{Um estranho silêncio}

A partir do exposto até aqui, fica clara a forte presença da filosofia da ciência nas pesquisas em ensino de ciências na forma de temas e referenciais que inspiram as diversas propostas relativas à NdC (DUSCHL; GRANDY, 2013). Contudo, podemos (e devemos) nos perguntar: onde se encontra o ensino de filosofia (da ciência) nesta discussão? Curiosamente, enquanto há acordo geral de que elementos de filosofia da ciência devem ser introduzidos nas aulas de ciências, sobretudo como parte das discussões sobre $\mathrm{NdC}$, ensinar efetivamente filosofia da ciência na Educação Básica é algo raramente considerado na literatura de língua inglesa.

Por exemplo, Allchin (2011), ao defender que a NdC seja ensinada por meio de estudos de caso e tendo como objetivo que os alunos aprendam a aferir a confiabilidade de afirmações e argumentos que envolvam temas científicos em situações concretas, considera que discussões propriamente filosóficas são irrelevantes:

\footnotetext{
"O que é um experimento?" No contexto da ciência na tomada de decisões pessoais e sociais, essa questão é metafísica e irrelevante. O que importa é se a evidência, derivada de experimento ou observação - ou qualquer outro meio - é confiável. O conceito clássico de controle (observações paralelas diferindo em uma única variável), em contraste, é fundamental, seja aplicado a
} 
um experimento no laboratório ou estudo de campo, um experimento natural, ou análise estatística de um grande conjunto de dados. Filosofar sobre a natureza abstrata do experimento pode ser deixado para... bem, filósofos. (ALLCHIN, 2011, p. 523)

Ao mesmo tempo, Hodson (2009) ao escrever um livro sobre a inclusão da história e da filosofia da ciência no ensino de ciências, faz questão de enfatizar, logo no prefácio, que:

Eu categoricamente não estou argumentando a favor de um curso formal em história, filosofia e sociologia da ciência. Em sua forma não diluída, HFC (História e Filosofia da Ciência) seria exigir demais para a maioria dos estudantes em idade escolar. Mais importante, seria muito árido para interessar a mais do que um punhado de estudantes. (HODSON, 2009, p. ix)

A rejeição da ideia de se ensinar filosofia da ciência aos estudantes da educação básica nesses autores pode ser ao menos parcialmente explicada pelo fato de que, em países de língua inglesa, o ensino de filosofia na escola tradicionalmente se restringe a casos excepcionais, sendo predominantemente ausente (UNESCO, 2007). Além disso, é possível argumentar que a aula de ciências não pode deixar de sê-lo para transformar-se num curso de filosofia. Isso não seria nem possível (o professor de ciências, afinal, não é um professor de filosofia) e nem desejável (não se pode deixar de ensinar ciências para ensinar filosofia).

Contudo, em outros países, dentre eles o Brasil, a situação é diferente. Há aulas de filosofia nas escolas, ministradas por professores com formação específica. Há livros didáticos de filosofia que incluem conteúdos de filosofia da ciência. E a experiência nesses países (UNESCO, 2007, 2009, 2011) mostra que, diferentemente do que defende Hodson, é possível ensinar filosofia da ciência na escola.

É preciso ter claro que as perspectivas dos dois lados não são as mesmas. A função do professor de ciências é ensinar ciências, e entende-se que a introdução de elementos de história e filosofia da ciência contribua para este processo por permitir uma melhor compreensão da NdC. Já a função do professor de filosofia é ensinar filosofia, o que inclui filosofia da ciência. Há, contudo, uma convergência no que diz respeito à ideia de que a filosofia da ciência pode contribuir para a educação do sujeito, tanto de uma perspectiva quanto de outra. Assim, seria de se esperar uma comunicação e um intenso intercâmbio entre pesquisadores de ensino de ciências e de ensino de filosofia. O que parece reinar, contudo, é um estranho silêncio.

Trata-se de um quadro no mínimo excêntrico se pensarmos na perspectiva do aluno: o professor de ciências e o professor de filosofia tratam de temas semelhantes, porém de maneiras que não dialogam entre si, e por vezes podem até mesmo se colocar em franca contradição! Só recentemente algumas vozes têm parecido tentar romper esse silêncio, reconhecendo a importância de que a comunidade de ensino de ciências volte seu olhar para 
o que dizem as pesquisas em ensino de filosofia. Por exemplo, Kötter e Hammann (2017) se opõem ao ensino de consensos gerais em $\mathrm{NdC}$ e defendem um ensino que incorpore as controvérsias metacientíficas como maneira de formar alunos reflexivos aptos a lidarem com disputas sociopolíticas. Os autores advogam a "competência epistêmica", no sentido de capacidade de refletir criticamente sobre aspectos do conhecimento científico, como objetivo de aprendizagem relevante e possível de ser alcançado pelos alunos. Ao fazê-lo, os autores se baseiam nos documentos oficiais da área de ensino de filosofia nas escolas alemãs.

\section{Considerações finais}

No presente artigo procuramos mostrar como, na pesquisa em ensino de ciências, há uma preocupação de longa data com a inclusão de elementos de filosofia da ciência por reconhecerse que esses podem contribuir para que o aluno tenha uma melhor compreensão da NdC, a qual, por sua vez, é dimensão fundamental da alfabetização científica e, portanto, objetivo importante do ensino de ciências. Enfatizamos, ainda, que mesmo que haja uma convergência no que se refere à temática da filosofia da ciência na educação, o que há é uma ausência de diálogo entre as comunidades de ensino de filosofia e ensino de ciências. Enquanto ambas, cada uma com seus objetivos, perspectivas e abordagens próprios, poderiam somar esforços com vistas ao papel da filosofia da ciência na educação, o que se vê é um silêncio que as divide.

O Brasil, assim como outros países que incluem o ensino de filosofia em seus sistemas de ensino, apresenta, contudo, as condições para a superação desse silêncio. O engajamento das duas comunidades em diálogo é essencial para tal superação. Para tanto, é preciso que o ensino de filosofia leve em consideração as contribuições do ensino de ciências para pensar a melhor forma de se levar a filosofia da ciência ao aluno.

Ao mesmo tempo, o ensino de filosofia pode e deve contribuir para qualificar a introdução de elementos filosóficos nas aulas de ciências. Por fim, e acima de tudo, é preciso que educadores de filosofia e de ciências dialoguem tendo em vista o aluno como foco maior de todos os seus esforços, ou seja, pensando em como suas ações articuladas contribuem para a educação do aluno.

\section{Referências}

ALLCHIN, D. Evaluating knowledge of the nature of (whole) science. Science Education, v. 95, n. 3, p. 518-542, 2011.

ALLCHIN, D. Teaching the Nature of Science: Perspectives \& Resources. Saint Paul: SHiPS Education Press, 2013.

AZEVEDO, N. H.; SCARPA, D. L. Revisão Sistemática de Trabalhos sobre Concepções de Natureza da Ciência no Ensino de Ciências. Revista Brasileira de Pesquisa em Educação em Ciências, v. 17, n. 2, p. 579-619, 2017. 
DAGHER, Z. R.; ERDURAN, S. Reconceptualizing the Nature of Science for Science Education. Science \& Education, v. 25, n. 1-2, p. 147-164, 2016.

DUSCHL, R. A.; GRANDY, R. Two Views About Explicitly Teaching Nature of Science.

Science \& Education, v. 22, n. 9, p. 2109-2139, 2013.

HODSON, D. Teaching and Learning about Science - Language, Theories, Methods, History, Traditions and Values. Rotterdam: Sense Publishers, 2009.

HODSON, D. Nature of Science in the Science Curriculum: Origin, Development, Implications and Shifting Emphases. In: MATTHEWS, M. R. (Ed.). International Handbook of Research in History, Philosophy and Science Teaching. Dordrecht: Springer, 2014. p. 911-970.

IRZIK, G.; NOLA, R. A Family Resemblance Approach to the Nature of Science for Science Education. Science and Education, v. 20, n. 7, p. 591-607, 2011.

JENKINS, E. W. The "nature of science" in the school curriculum: the great survivor. Journal of Curriculum Studies, v. 45, n. 2, p. 132-151, 2013.

KAMPOURAKIS, K. The "general aspects" conceptualization as a pragmatic and effective means to introducing students to nature of science. Journal of Research in Science Teaching, v. 53, n. 5, p. 667-682, 2016.

KÖTTER, M.; HAMMANN, M. Controversy as a Blind Spot in Teaching Nature of Science Why the Range of Different Positions Concerning Nature of Science Should Be an Issue in the Science Classroom. Science \& Education, v. 26, n. 5, p. 451-482, 2017.

LEDERMAN, N. Students' and teachers' conceptions of the nature of science: A review of the research. Journal of research in science teaching, v. 29, n. 4, p. 331-359, 1992.

LEDERMAN, N. G. et al. Views of Nature of Science Questionnaire: Toward Valid and Meaningful Assessment of Learners' Conceptions of Nature of Science. Journal of Research in Science Teaching, v. 39, n. 6, p. 497-521, 2002.

LEDERMAN, N. G. Nature of Science: Past, Present and future. In: ABELL, S. K.; LEDERMAN, N. G. (Eds.). Handbook Of Research On Science Education. New York and London: Routledge Taylor \& Francis Group, 2007. p. 831-879.

LEDERMAN, N. G.; BARTOS, S. A.; LEDERMAN, J. S. The Development, Use, and Interpretation of Nature of Science Assessments. In: MATTHEWS, M. R. (Ed.). International Handbook of Research in History, Philosophy and Science Teaching. Dordrecht: Springer, 2014. p. 971-997.

MATTHEWS, M. R. Science Teaching: The Role of History and Philosophy of Science. New York and London: Routledge, 1994.

MATTHEWS, M. R. Thomas Kuhn's Impact on Science Education: What Lessons Can Be 
Learned? Science Education, v. 88, n. 1, p. 90-118, 2004.

MATTHEWS, M. R. Changing the Focus: From Nature of Science (NOS) to Features of Science (FOS). In: KHINE, M. S. (Ed.). Advances in Nature of Science Research. Dordrecht: Springer, 2012. p. 3-26.

MATTHEWS, M. R. (ED.). International Handbook of Research in History, Philosophy and Science Teaching. Dordrecht: Springer, 2014.

MATTHEWS, M. R. Science Teaching The Contribution of History and Philosophy of Science 20th Anniversary Revised and Expanded Edition. 2nd. ed. New York: Routledge, 2015.

OLIVEIRA, T. L. T. O Ensino de Filosofia Pensado à Luz de Algumas Questões da Filosofia da Ciência. Revista Digital de Ensino de Filosofia, v. 3, n. 1, p. 91-106, 2017.

PLASTINO, C. E. O ensino de filosofia das ciências naturais no secundário. In: NETO, H. N. (Ed.). O Ensino da Filosofia no Segundo Grau. São Paulo: SEAF/ Sofia, 1986.

SASSERON, L. H.; CARVALHO, A. M. P. DE. Alfabetização científica: uma revisão bibliográfica. Investigações em Ensino de Ciências, v. 16, n. 1, p. 59-77, 2011.

UNESCO. Philosophy A School of Freedom. Paris: [s.n.].

UNESCO. Teaching Philosophy in Latin America and the Caribbean. Paris: UNESCO, 2009.

UNESCO. Teaching Philosophy in Europe and North America. Paris: UNESCO, 2011.

\section{Correspondência}

Daniela Lopes Scarpa - Rua do Matão, 321, travessa 14, sala 361, Cidade Universitária, CEP 05.508-090, São Paulo, São Paulo, Brasil.

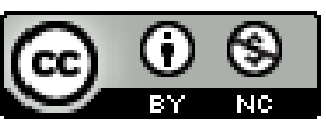

This work is licensed under a Creative Commons Attribution-NonCommercial 4.0 International (CC BY-NC 4.0) 